\title{
Anti-inflammatory Effects of Enhanced Recovery Programs on Early-Stage Colorectal Cancer Surgery
}

\author{
Aurélien Venara $^{1,2,3} \cdot$ Emilie Duchalais ${ }^{1,4} \cdot$ Anne Dariel $^{1,5} \cdot$ Philippe Aubert $^{1}$ • \\ Tony Durand ${ }^{1} \cdot$ Guillaume Meurette $^{1,4,5} \cdot$ Malvyne Rolli-Derkinderen $^{1,5}$. \\ Antoine Hamy ${ }^{2,3} \cdot$ Michel Neunlist $\mathbf{t}^{1,4,5}$
}

Published online: 5 October 2017

(C) Société Internationale de Chirurgie 2017

\begin{abstract}
Background Postoperative ileus (POI) is observed in 20-30\% of patients undergoing colorectal cancer surgery, despite enhanced recovery programs (ERPs). Cyclooxygenase (COX)-2 is identified as a key enzyme in POI, but other arachidonic acid pathway enzymes have received little attention despite their potential as selective targets to prevent POI. The objectives were to compare the expression of arachidonic acid metabolism (AAM) enzymes (1) between patients who underwent colorectal cancer surgery and followed an ERP or not (NERP), (2) and between ERP patients who experimented POI or not and (3) to determine the ability of antagonists of these pathways to modulate contractile activity of colonic muscle.

Methods This was a translational study. Main outcome measures were gastrointestinal motility recovery data, $m R N A$ expressions of key enzymes involved in AAM (RT-qPCR) and ex vivo motility values of the circular colon muscle. Twenty-eight prospectively included ERP patients were compared to eleven retrospectively included NERP patients that underwent colorectal cancer surgery.

Results ERP reduced colonic mucosal COX-2, microsomal prostaglandin E synthase (mPGES1) and hematopoietic prostaglandin D synthase (HPGDS) $m R N A$ expression. mPGES1 and HPGDS $m R N A$ expression were significantly associated with ERP compliance (respectively, $r 2=0.25, p=0.002$ and $r 2=0.6, p<0.001$ ). In muscularis propria, HPGDS $m R N A$ expression was correlated with GI motility recovery $(p=0.002)$. The pharmacological inhibition of mPGES1 increased spontaneous ex vivo contractile activity in circular muscle $(p=0.03)$.

Conclusion The effects of ERP on GI recovery are correlated with the compliance of ERP and could be mediated at least in part by mPGES1, HPGDS and COX-2. Furthermore, mPGES1 shows promise as a therapeutic target to further reduce POI duration among ERP patients.
\end{abstract}

Work accepted as an oral communication at the Clinical Congress of the American College of Surgeons, Washington DC, 2016 October 16-20 and as an oral communication at the Clinical Congress of the French Association of Surgery, Paris, 2017 September.

Electronic supplementary material The online version of this article (doi:10.1007/s00268-017-4266-2) contains supplementary material, which is available to authorized users.

Aurélien Venara

auvenara@yahoo.fr

Michel Neunlist

Michel.neunlist@univ-nantes.fr
1 TENS - The enteric nervous system in gut and brain disorders, INSERM U1235, 44093 Nantes, France

2 L'UNAM, University of Angers, Angers, France

3 Department of Digestive and Endocrinal Surgery, University Hospital of Angers, 4 rue Larrey, 49933 Angers Cedex 9, France

4 CHU Nantes, Hotel Dieu, Institut des maladies de l'Appareil Digestif, 44093 Nantes, France

5 L'UNAM, University of Nantes, Nantes, France 


\section{Introduction}

Postoperative ileus (POI) has a significant effect on patient well-being and, furthermore, increases morbidity and length of stay $[1,2]$. The cost of hospitalization for patients with POI is twice that of patients without POI [2], attaining $\$ 750$ million annually in the USA [1,3]. A range of preventive and/or therapeutic strategies has been proposed to reduce the duration of POI. These include pharmacological intervention (prokinetics and/or anti-inflammatory agents) [4-6], vagal stimulation [7] via mastication [8,9] and early feeding programs $[10,11]$. Enhanced recovery programs (ERPs), recently proposed by the ERAS Society [12, 13], organize most of these strategies into a perioperative protocol. ERPs have been shown to improve the postoperative course considerably, reduce length of stay and decrease morbidity [14]. Furthermore, they reduce the duration and occurrence of POI itself $[15,16]$. However, between 20 and $30 \%$ of patients who undergo colorectal surgery will still have POI 4 days after the intervention, despite the use of ERPs [15]. Therefore, reducing the duration of POI is aimed at improving postoperative outcomes, reducing hospitalization and enabling safe outpatient management after colectomies. Research teams have looked at approaches such as nicotinic chewing gums to improve vagal stimulation $[17,18]$ or prokinetic drugs [19] to make ERPs more effective, but their results fell short of therapeutic expectations. Consequently, POI remains an issue in medical care.

POI affects the entire gastrointestinal tract [20], but most of the strategies described above and most studies in the literature target the small bowel, especially by activating vagal pathways. Indeed, the density of parasympathetic innervation decreases along a rostrocaudal gradient to become low (to inexistent) in the distal bowel [21], which means that these strategies most likely have only a limited effect on the colon. As a result, other strategies targeting colonic activity specifically are necessary to improve POI management and prevention. As previously shown by Schwarz et al., selective small bowel manipulation leads to pan-digestive inflammation [20] via cyclooxygenase (COX)-2. As such, targeting the arachidonic acid (AA) pathway may be of interest.

AA metabolism [22-24] leads to the synthesis of prostaglandin D2 (PGD2), prostaglandin E2 (PGE2), prostacyclin (PGI2) and thromboxanes via COX-1 and COX-2. COX-2 has been shown to play a key role in POI, inducing the synthesis of PGD2 and PGE2 in rodents and humans; on the one hand, surgical manipulation increases COX-2 expression [22], and on the other hand, COX-2 inhibition (pharmacological or genetic) reduces the duration of surgically induced POI [25]. PGE2 and PGD2 are lipid mediators produced by the activation of COX-2 pathways via microsomal prostaglandin E synthase (mPGES1) and hematopoietic prostaglandin D synthase (HPGDS) or lipocalin-type prostaglandin D synthase (LPGDS), respectively. Increasingly, PGE2 appears to be involved in POI. Animal studies have shown that PGE2 reduces motility via activation of EP2 and EP4 receptors [26, 27] and that its concentration increases as a result of surgery [28]. Concerning PGD2, its functional effects on GI motility remain controversial given that it increases contractile activity in rat colon [29] and reduces sensitivity to pressure-induced peristalsis in guinea pigs [30]. However, the impact of POI on mPGES1 or HPGDS expression and their involvement are currently unknown, especially in humans.

The aim of this study was to compare the expression of arachidonic acid metabolism (AAM) enzymes (1) between patients who underwent colorectal tumor resection and followed an ERP or not (NERP), (2) between ERP patients who experienced or did not experience POI and (3) to determine the ability of antagonists of these pathways to modulate the contractile activity of the colonic muscle in order to propose new therapeutics to improve ERP, from bench to bedside.

\section{Materials and methods}

\section{Patients}

Twenty-eight patients who underwent colorectal surgery for endoscopically unresectable cancer or polyp in a single center between January 2015 and January 2016 and who followed a perioperative ERP were enrolled in the ERP group. These patients were retrospectively selected so that we could create 2 comparable groups of patients: One that experienced POI and the other that did not.

Criteria for non-inclusion were:

- Medical history of esophageal or gastric surgery;

- Treatments modifying the metabolism of acetylcholine;

- Indication for enterostomy;

- Postoperative general complications potentially associated with postoperative ileus, such as septic shock or anastomotic leakage.

Data for the ERP group were prospectively collected from an anonymized database. We note that some of these patients were included in a previous study in which we concluded that ERPs influence POI [15]. The ERP followed in our center is described in this essay [15]. None of the above-mentioned patients underwent preoperative chemotherapy.

The ERP group was compared to a historical cohort of 11 patients who underwent colorectal tumor resection, but 
did not follow an ERP (NERP). This historical cohort came from the biobank of another center in which ERP was not implemented at the moment of tissue collection. Data for the NERP group were collected retrospectively. Differences between ERP and NERP management (pre- and perioperative) are reported in Table 1.

None of the patients included in this essay received pre-, peri- or postoperative non-steroidal anti-inflammatory drugs (NSAIDs).

Data collected for the two groups were:

1. Patient characteristics: gender, medical history, surgical history, treatment;

2. Operative data: surgical access, anesthesia, intervention, type of anastomosis;

3. Postoperative data: delay to first flatus, delay to first stool, delay to GI motility recovery, postoperative morbidity, POI occurrence, length of stay, compliance to ERP;

4. Cancer information: Dukes Stage.

\section{Definitions of clinical outcomes}

GI functions were assessed using the delays to first flatus, first stool and GI motility recovery. Delay to GI motility recovery was defined using the endpoint described by Van Bree et al. [31]. Motility was considered as recovered when patients had stools and tolerated solid food [32].

POI was defined as per Vather et al. [32] and diagnosed when two or more of the following symptoms were present after 4 days:

- Nausea or vomiting in the preceding $12 \mathrm{~h}$;

- Inability to tolerate a solid or semisolid oral diet for the preceding two meals;

- Abdominal distension;
- Absence of flatus and stool in the preceding $24 \mathrm{~h}$;

- Radiological evidence of ileus on plain abdominal radiography or abdominal computed tomography in the preceding $24 \mathrm{~h}$.

\section{Biobanks}

Tissues from the patients who followed the ERP were stored in the biobank of the Biological Resources Center of Angers (BB-0033-00038) and registered under the number CB-2011-05. Tissues from the historical cohort were stored in the biobank of IMAD (Institut des maladies de l'appareil digestif, the Institute for Diseases of the Digestive System) and registered under number DC-2008-402. Concerning the historical cohort, only mucosa/submucosa samples were available for this study. Both biobanks were approved by the French Ministry of Science and Research. All patients gave their informed and written consent for the study.

\section{Tissue conditioning}

Tissue fragments $(\sim 1 \mathrm{~cm} \times 1 \mathrm{~cm})$ were collected from the proximal (left colectomy) or distal (right colectomy) extremity of the resected colon away from the tumor in a macroscopically normal area. Fragments of mucosa/submucosa and muscularis propria/serosa were macroscopically separated. To simplify the manuscript, the first fragment will be called mucosa and the second one will be called muscularis propria in the results.

Fragments from the ERP group were stored in liquid nitrogen at $-80{ }^{\circ} \mathrm{C}$. The delay to congelation ranged from 30 to $45 \mathrm{~min}$.

Table 1 Differences in management between ERP program and traditional program performed before the surgical specimen collection

\begin{tabular}{lcc}
\hline & ERP program & Traditional program \\
\hline Preoperative & + & - \\
Patient information & + & - \\
Immuno-nutrition (7 days) & + & - \\
Carbohydrate loading & & - \\
Fasting $<6$ h (solids) & - & - \\
$<2$ h (liquids) & & \pm \\
Oral bowel preparation & \pm & - \\
Perioperative & + & - \\
Laparoscopic access & + & \\
Reduction in intravenous liquid intake & + & \\
Nausea/vomiting prevention & & \\
\hline
\end{tabular}






\section{Quantitative polymerase chain reaction (qPCR) analysis}

Total RNA was extracted from the samples (mucosa/submucosa and muscularis propria/serosa), using Nucleospin RNA II (Macherey-Nagel, Hoerdt, France). cDNA was synthetized using Superscript III Reverse Transcriptase (Thermo Fisher Scientific, Courtaboeuf, France) according to the manufacturer's recommendations. Real-time PCR was performed using the Fast Sybr Green Master Mix kit (Applied Biosystems, California, USA) and run on a StepOnePlus thermocycler (Applied Biosystems, California, USA).

Each qPCR product was directly loaded onto non-denaturing $2 \%$ agarose gel and visualized under UV transillumination. Specificity of the primers was determined by sequencing the PCR products. Genes studied were cyclooxygenase 1 and 2 (COX-1 and COX-2), microsomal prostaglandin E synthase (mPGES1), hematopoietic prostaglandin D synthase (HPGDS) and lipocalin-type prostaglandin D synthase (LPGDS).

Primer sequences were:

\begin{tabular}{|c|c|}
\hline $\begin{array}{l}\text { Homo sapiens, COX- } \\
1 \text { (NM 000962.2) }\end{array}$ & Fw: $5^{\prime}$ TCCTGTTGGTGGACTATGG $3^{\prime}$ \\
\hline & Rev: $5^{\prime}$ GTGGTGGTCCATGTTCCTG 3' \\
\hline Homo sapiens, COX- & Fw: $5^{\prime}$ TGGGAAGCCTTCTCTAACCTC $3^{\prime}$ \\
\hline & $\begin{array}{l}\text { Rev: } 5^{\prime} \text { TCAGGAAGCTGCTTTTTACCTT } \\
3^{\prime}\end{array}$ \\
\hline Homo sapiens, & Fw: 5' AGAAGAAGGCGGCGTTGTCC $3^{\prime}$ \\
\hline & $\begin{array}{l}\text { Rev: } 5^{\prime} \text { CCACCACTGACACGGAGTAGG } \\
\quad 3^{\prime}\end{array}$ \\
\hline $\begin{array}{l}\text { Homo sapiens, } \\
\text { HPGDS }\end{array}$ & $\begin{array}{l}\text { Fw:5'GAGAATGGCTTATTGGTAACTCT } \\
\text { GT 3' }\end{array}$ \\
\hline & $\begin{array}{l}\text { Rev: } 5^{\prime} \\
\text { AAAGACCAAAAGTGTGGTACTGC } 3^{\prime}\end{array}$ \\
\hline $\begin{array}{l}\text { Homo sapiens, } \\
\text { mPGES1 } \\
\text { (NM_004878.4) }\end{array}$ & Fw: 5' CGCTGCTGGTCATCAAGA $3^{\prime}$ \\
\hline & Rev: 5' CGTGTCTCAGGGCATCCT \\
\hline
\end{tabular}

Expression of the gene of interest was normalized to the expression of the ribosomal protein S6 gene (S6), which was measured in parallel as an internal control. All experiments were analyzed using StepOnePlus software.

If the difference in $C_{\mathrm{t}}$ values of duplicates was larger than two, and the mean was larger than the lowest $C_{\mathrm{t}}$ value 
of the white duplicates, patients were excluded from the analysis for the gene.

\section{Ex vivo muscle motility studies}

Seven tissue samples from patients not included in the ERP or NERP groups were collected and used immediately to perform a motility assessment. These patients underwent colorectal resection and followed an enhanced recovery program. After their surgical resection, the samples were immediately placed in cold HBSS for transfer to the laboratory. Strips of circular and longitudinal muscle were dissected and placed in an organ bath (Radnoti, California, USA) with $15 \mathrm{~mL}$ of Krebs solution at $37{ }^{\circ} \mathrm{C}$, continuously bubbled with $95 \% \quad \mathrm{O}_{2}$ and $5 \% \quad \mathrm{CO}_{2}$. The contractile responses of the muscle strips were continuously recorded using isometric force transducers (No. TRI202PAD, Panlab, Cornellã, Spain) coupled to a computer equipped with the PowerLab 8/30 system and LabChart data analysis software (AD Instruments, Spechbach, Germany). The strips were stretched with a preload of $1 \mathrm{~g}$, which was maintained for an equilibration period of $60 \mathrm{~min}$. Thereafter, they were subjected to electrical field stimulation (EFS) using a STG 4008 MCS electrical stimulator (Multi Channel Systems, Reutlingen, Germany). EFS parameters were: train duration, $10 \mathrm{~s}$; pulse frequency, $20 \mathrm{~Hz}$; pulse duration, $400 \mu \mathrm{s}$; and pulse amplitude, $11 \mathrm{~V}$. This procedure was repeated three times at 10-min intervals. Then, $15 \mu 1$ of the drugs listed hereafter was added to the baths and after $30 \mathrm{~min}$ of incubation, the same EFS stimulation protocol was repeated.

Drugs were (1) a mPGES1 inhibitor (CAY10589) used at a final concentration of $10 \mu \mathrm{M}$ (Cayman Chemical, Ann Arbor, USA) and (2) prostaglandin D synthase (hematopoietic type) inhibitor I (HPGDS inhibitor I) used at a final concentration of $1 \mu \mathrm{M}$ (Cayman Chemical). Both were solubilized in DMSO at a concentration of 10 and $1 \mathrm{mM}$, respectively. Concentrations were determined according to the furnisher recommendations. Contractile activity was evaluated by measuring the area under the curve (AUC). Spontaneous contractile activity was evaluated by measuring the AUC for 2 min before the first EFS. The EFS-induced response was evaluated by measuring the AUC during the EFS period and 1 min after stimulation.

The amplitudes of spontaneous and induced contractions were also measured during the same period.

\section{Statistical analyses}

Statistical analyses were performed using SPSS version 15.0 (SPSS Inc., Chicago, IL) and Prism software. Data were expressed as median (interquartile range). The MannWhitney $\mathrm{U}$ test was performed to compare non-normal continuous variables. Linear regressions were done for variables likely to have an association with delay to recovery. $p<0.05$ was considered as significant.

\section{Results}

\section{ERP versus NERP patients}

Overall, 39 patients were included. Twenty-eight were men $(71.8 \%)$, and the median body mass index was $27 \mathrm{~kg} / \mathrm{m}^{2}$. On baseline, patients were comparable (supplementary file 1) apart for diabetes occurrence, which was more frequent in the NERP group $(p=0.040)$, and ASA score that was higher in NERP group $(p=0.030)$. The rate of surgical laparoscopic access was higher in the ERP group $(p<0.005)$, but this difference was expected because surgical access was an item of the ERP.

\section{Arachidonic acid metabolism and enhanced recovery programs}

We first characterized the impact of ERP on the presence of mucosal $m R N A$ for enzymes involved in AA metabolism. There was no significant modification of mucosal $m R N A$ expression for COX-1 and LPGDS observed in the ERP group in comparison with the NERP group. Interestingly, however, COX-2, mPGES1 and HPGDS $m R N A$ expressions were significantly reduced by, respectively, 19-fold $(p=0.015), 12$-fold $(p<0.001)$ and 8 -fold $(p=0.004)$ in ERP patients compared to NERP patients (Fig. 1).

\section{Impact of items of enhanced recovery programs on arachidonic metabolism}

Given that laparoscopic access reduces postoperative inflammation (33), we aimed to determine whether the difference in $m R N A$ expression between groups was exclusively due to this item. Interestingly, comparing patients undergoing laparoscopy (L) and those undergoing laparotomy (NL), HPGDS $m R N A$ expression was higher in group NL $(p=0.006)$, but COX-2 and mPGES1 $m R N A$ expressions were not significantly different between groups (respectively, $p=0.648$ and $p=0.060$ ) (Fig. 2).

Furthermore, in linear regression, we found that HPGDS and mPGES1 $m R N A$ expressions were associated with the number of items of ERP compliance (respectively, $r 2=0.60, p<0.0001$ and $r 2=0.25, p=0.002$ ) (Fig. 3), but COX-2 was not $(r 2=0.01, p=0.588)$. 


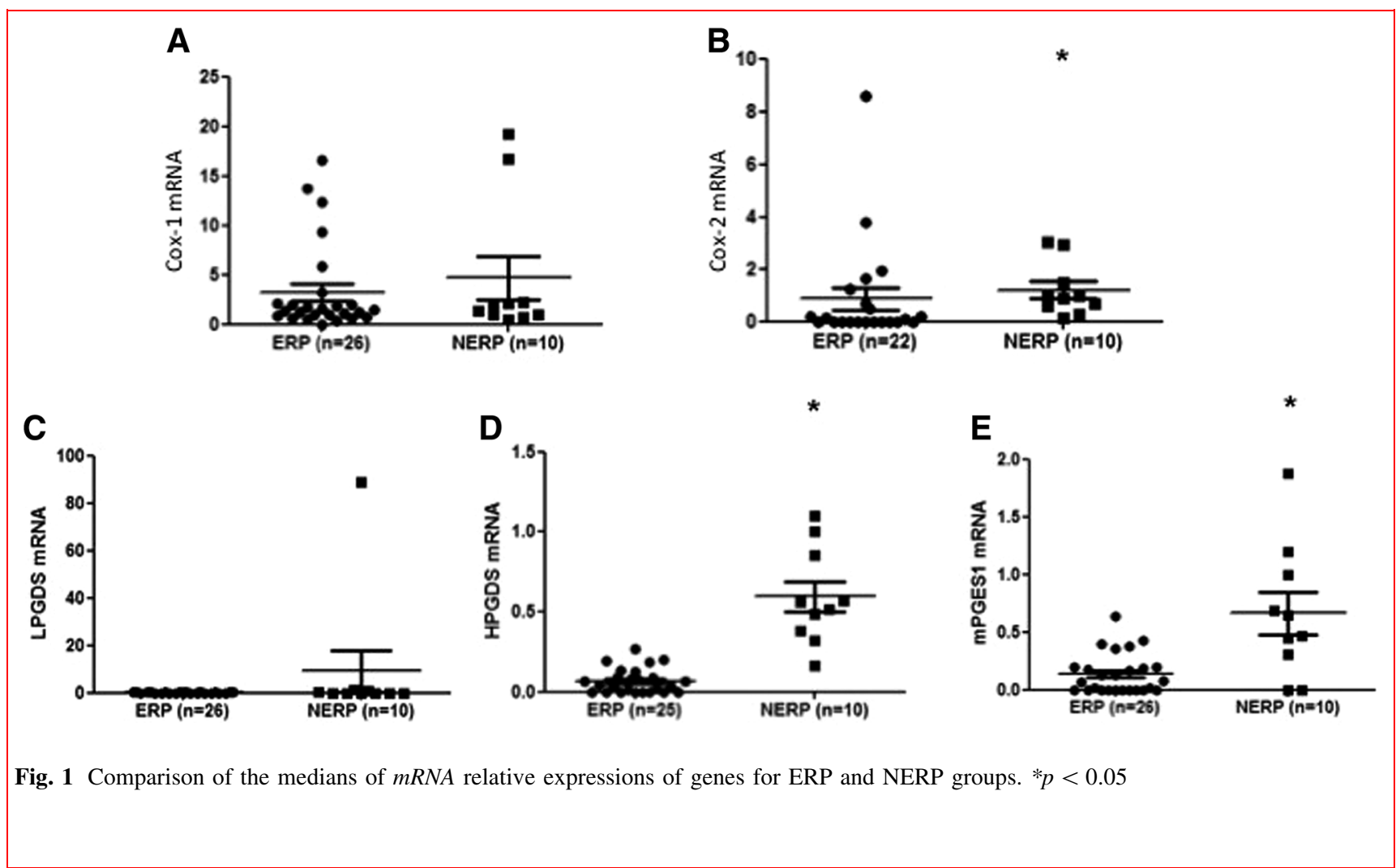

Acid arachidonic metabolism and postoperative ileus in patients following an enhanced recovery program

We then aimed to determine whether, within the ERP patient population, $m R N A$ expression for enzymes involved in AA metabolism was associated with POI (POI patients) and postoperative GI motility recovery.

First, we determined that mucosal $m R N A$ expression of the present genes of interest was similar between POI and non-POI (NPOI) patients (Table 2 and Fig. 4a, b, c). Second, we characterized the expression of these genes in the muscularis propria and found no change in COX-2 $(p=0.08)$, mPGES1 $(p=0.90)$ or HPGDS $(p=0.85)$ $m R N A$ expressions between POI and NPOI patients (Fig. 5a, b, c).

Third, we determined whether $m R N A$ expression for enzymes involved in AA metabolism correlated with GI function recovery elements, i.e., delay to first flatus, first stool and GI motility recovery (Table 2). Mucosal HPGDS $m R N A$ expression was not significantly associated with delay to first flatus $(r 2=0.13 ; p=0.07)$. In mucosal specimens, no difference in mRNA expression was found for all genes (Fig. 4d, e, f; Table 2). In the muscularis propria, COX-2 $m R N A$ relative expression was significantly correlated with delay to first flatus $(p=0.04)$. Furthermore, HPGDS $m R N A$ relative expression was significantly correlated with first stool (Table $2 ; p<0.008$ ) and delay to GI motility recovery (Fig. $5 f ; r 2=0.22$; $p=0.002$ ). However, mPGES1, COX-2 and LPGDS $m R N A$ expressions were not significantly correlated with GI function recovery (Table 2; Fig. 5d, e).

\section{Impact of HPGDS inhibitor I and mPGES1 inhibitor on ex vivo colon motility}

In the final step, to determine whether AAM located downstream of COX-2 and associated with recovery of GI motility in vivo could affect GI motility ex vivo, we characterized the effects of specific HPGDS (HPGDS inhibitor I) and mPGES1 (CAY10589) inhibitors on the ex vivo contractile activity of colonic circular muscle strips.

DMSO, at the drug equivalent final concentration used to dissolve the antagonist (1:1000), had no effect on spontaneous muscle activity (Fig. 6a). Surprisingly, HPGDS inhibitor I had no effect on spontaneous colonic motor activity (Fig. 6b). 
Fig. 2 Comparison of the medians of $m R N A$ relative expressions of COX-2, mPGES1 and HPGDS in mucosa, according to the use of laparoscopic access or not (A, B, C). $*_{p}<0.05$
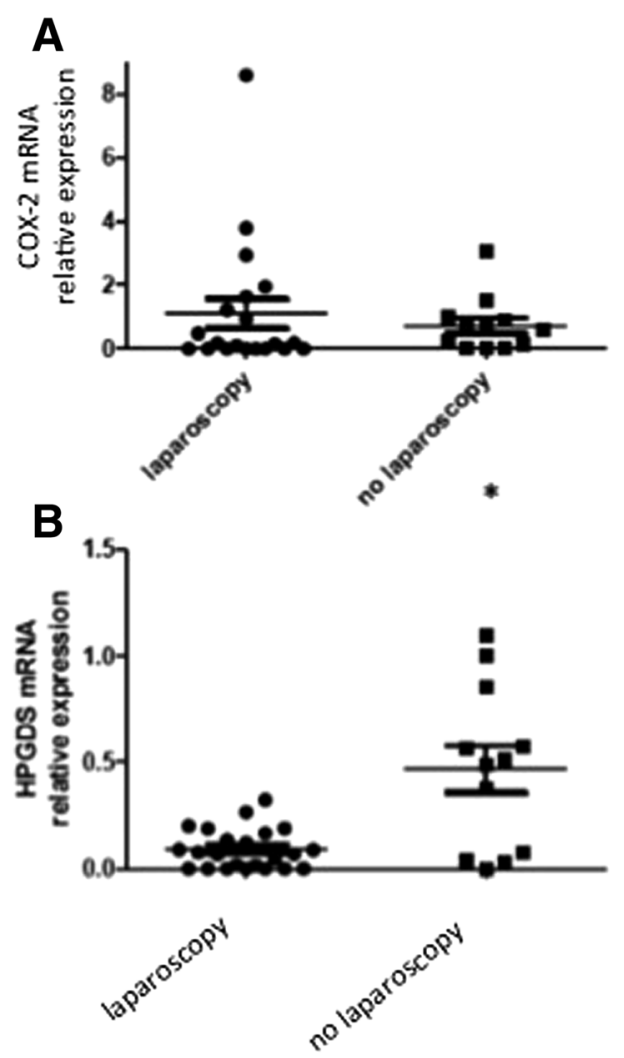

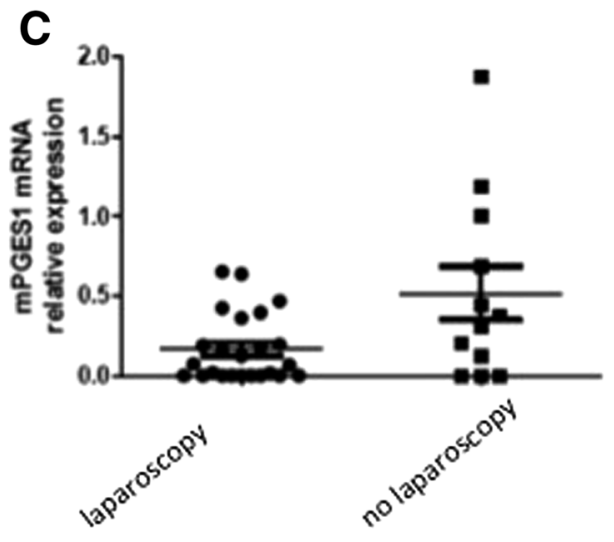

CAY10589 led to a significant increase in contractile activity ( $p=0.03 ; \mathrm{n}=7$ ) (Fig. 6c, d). Finally, there was no significant increase in the amplitude of the peak contraction ( $p=0.11 ; \mathrm{n}=7$ ) (Fig. 6e).

\section{Discussion}

In the present study, we first showed that patients who underwent colorectal tumor resection and followed an ERP had an early reduced colonic mucosal COX-2, mPGES1 and HPGDS $m R N A$ expression, when compared to colorectal resection patients who did not follow an ERP. Laparoscopic access has been thought to be the cause of this difference because it is known to reduce postoperative inflammation [33], and it was also used significantly more in the ERP group. However, we showed that it was not the only parameter involved in the reduction in $m R N A$ expressions. Indeed, only the HPGDS $m R N A$ expression differed between group L and NL $(p=0.006)$. Also, we showed that expressions of mPGES1 and HPGDS $m R N A$ were significantly reduced when the compliance with ERP increased (respectively, $p=0.002$ and $p<0.001$ ), while the COX-2 mRNA expression was not. Nevertheless, we cannot explain the reason why COX-2 was not influenced by the number of items followed. We think that this is most likely due to a smaller effect of ERP in reducing COX-2 $m R N A$, requiring a larger number of patients to have significant results. However, this is the first study that shows the role of EPRs in reducing inflammation involving AA metabolism.

This difference can be partly due to laparoscopy but also partly due to immuno-nutrition and carbohydrates loading. Indeed, immuno-nutrition is composed with a part of arginine. Arginine is involved in nitrogen (NO) metabolism. NO is involved in COX-2 activation [34]. It was shown that, in the early postoperative period, endogenous $\mathrm{NO}$ is a major inhibitory component of gastrointestinal motility in rats [35]. Carbohydrates intake, via an increase in blood insulin levels, may also be involved in this reduction in expression, due to the anti-inflammatory effects of insulin, as previously described [36]. Also, the other items of ERP are probably involved in inflammation reduction, but there is little evidence in the literature to explain the pathways and mechanisms of this reduction. However, our results argue for the fact that not only laparoscopy, but a high compliance of pre- and perioperative ERP reduces early induction of inflammation after colorectal surgery. A linear association between compliance to ERP and gastrointestinal motility recovery has been previously described [15] and can probably be linked to 
Fig. 3 Linear regressions of IRNA relative expressions of COX-2, mPGES1 and HPGDS according to the compliance of enhanced recovery programs (ERP) $(\mathrm{A}, \mathrm{B}, \mathrm{C})$
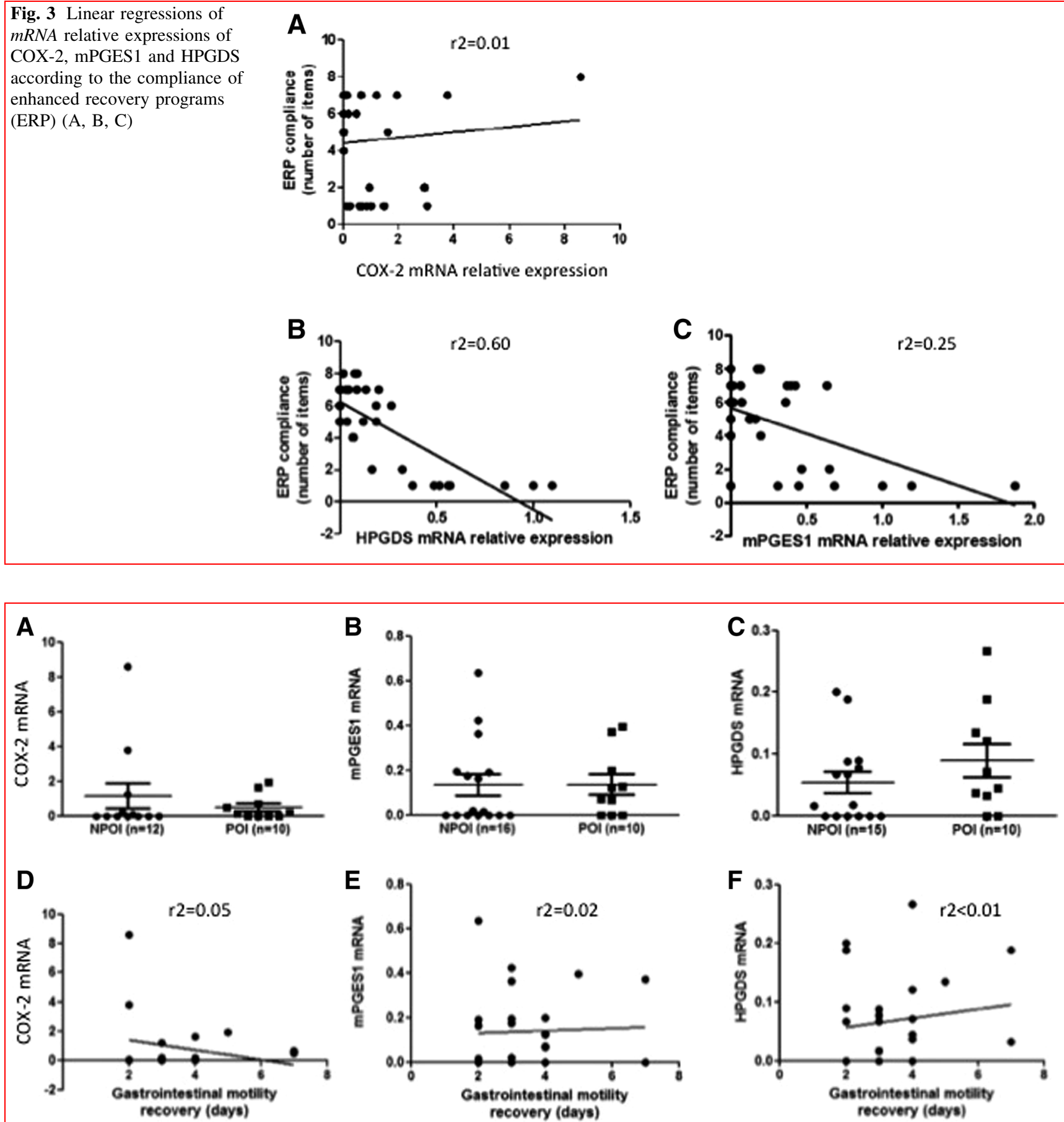

Fig. 4 Comparison of the medians of $m R N A$ relative expressions of COX-2, mPGES1 and HPGDS in mucosa, according to the occurrence (POI) or non-occurrence (NPOI) of postoperative ileus $(\mathbf{a}, \mathbf{b}, \mathbf{c})$, and linear regressions of $m R N A$ relative expressions of COX-2, mPGES1 and HPGDS according to delay to recovery of gastrointestinal functions $(\mathbf{d}, \mathbf{e}, \mathbf{f})$

this linear association between compliance and $m R N A$ expression.

To further understand POI pathways among ERP patients, we compared mRNA expression of key enzymes involved in AA metabolism between POI and NPOI patients. There was no significant difference, neither in the mисова nor in muscularis propria. However, HPGDS $m R N A$ expression was positively and linearly correlated with GI motility recovery $(p=0.002)$, whereas COX-2 $m R N A$ expression was only correlated with delay to first 


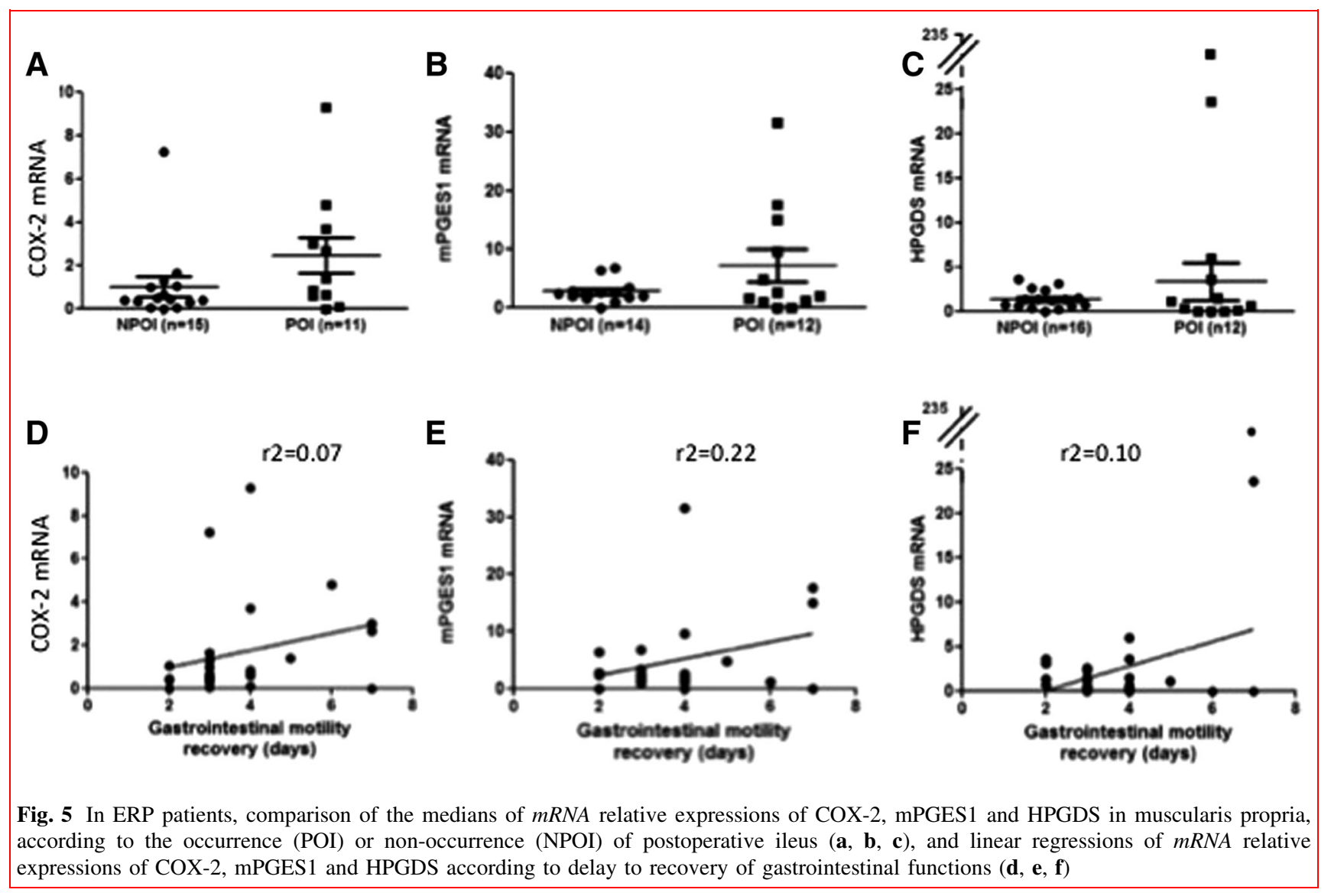

flatus $(p=0.04)$. This probably means that COX-2 and HPGDS have a residual role in POI despite ERP compliance. To assess their role in muscle contractile activity, we assessed the effect of ex vivo pharmacological inhibition of mPGES1 and HPGDS. mPGES1 inhibition increased spontaneous colon circular muscle contractile activity ex vivo in an organ bath $(p=0.03)$, whereas HPGDS did not. We did not assess the effect of COX-2 inhibition because other authors have shown its beneficial effects on muscle contractile activity [22] and because clinical use of COX-2 inhibitors is controversial due to their putative side effects, particularly a potential increase in the risk of anastomotic leakage [37-39]. The adverse effects of nonsteroidal anti-inflammatory drugs may be due in part to a blockade of upstream AA pathways, leading to a reduction in various prostanoids exhibiting both deleterious and beneficial effects, such as PGE2 and PGD2 synthesis. Therefore, new selective agents targeting pathways more specifically involved in POI would be of great interest. Similarly to COX-2, our results suggest that ERP reduces the expression of mPGES1, but that mPGES1 still has a role in gastrointestinal motility reduction that could be improved by mPGES1 inhibitors. From bench to bedside, we argue that mPGES1 could be a good novel therapy to prevent and/or treat POI after colorectal surgery for tumor.

However, our work contains some limitations due to its design and the ethical consideration of patient management. The main limitation was the use of two different cohorts, one prospective and the other retrospective. Furthermore, theses two groups were derived from different centers. Both, difference in data collection and provenience from different centers may negatively impact validity in our results.

The different provenience and processing of specimens, of note two different centers and lack of mucosa in NERP group, may represent a major bias concerning the comparison of mRNA expression between the two groups of tissue samples.

Some notable differences between our two populations, diabetes and higher ASA score in group NERP, were present. Although hyperglycemia has been shown to induce COX-2 synthesis [40], we do not think that the difference in diabetes rates had an influence on GI recovery, given that all patients were treated for the disease at the time of the study, which meant that hyperglycemia was absent. Regarding the ASA score, it could impact on the level of inflammation in the colon wall and could lead to an 
Fig. 6 Ex vivo motility study showing spontaneous contraction with DMSO (a), an inhibitor of mPGES1

(CAY10589; C) and HPGDS inhibitor 1 (b). Dotted line represents the time at which drugs were administered. Administration of CAY10589 results in an increase in spontaneous muscle contraction. D represents the AUC before and after administration of mPGES1 $(p=0.03)$ and E the maximal amplitude of muscle contraction before and after administration of mPGES1 $(p=0.11)$
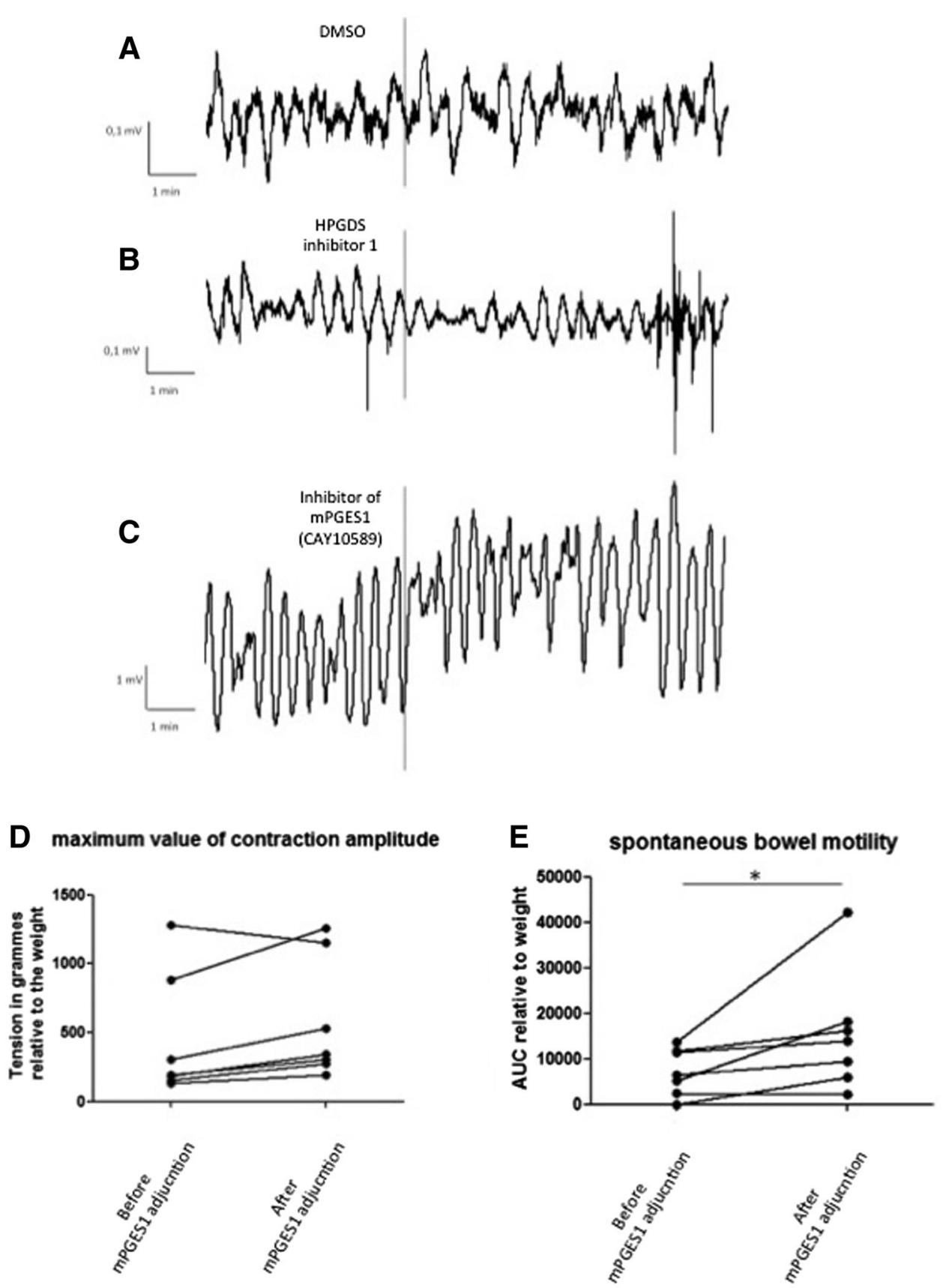

increase in significance of the differences between ERP and NERP group. However, this is probably not the only cause of this difference. Indeed, the population of ASA score $>3$ represents only 2 of 11 patients $(<20 \%)$, and moreover, we showed a significant correlation between inflammation markers and ERP leading to the conclusion that ERP reduces the inflammation in colon wall.

One other difference that has to be discussed is the conditions of storage that were different between ERP and
NERP groups. However, the delay between collection and freezing was the same. The only difference was the method of storage in the long term. All tissues were first frozen in liquid azote, and the duration of ischemia that could lead to an increase in inflammation was the same for both groups.

Finally, although the cohort of patients is small, the results are significant enough to argue that ERP should be fully complied with in order to have a selective anti- 
inflammatory effect after colorectal surgery and improve gastrointestinal motility recovery.

\section{Conclusion}

Our results suggest that pre- and perioperative phases of ERP prevent the activation of key enzymes of AA pathways, such as COX-2, LPGDS and mPGES1, and therefore reduce POI. Laparoscopic access is not the only parameter involved in the reduction in POI incidence, and a better compliance would reduce postoperative inflammation.

Furthermore, the effect of ERP on inflammation (and on POI) may be improved using pharmacological inhibition of mPGES1, but effects of the inhibition of this pathway have to be explored in animal models and further randomized clinical trials.

Acknowledgements The authors want to thank the staff of the Biological Resources Center of Angers (BB-0033-00038) and especially Dr Odile Blanchet, Mr Belaid Sekour, Miss Lydie Denechaud and Miss Dominique Couturier. The authors would also like to acknowledge the "Direction de la Recherche Clinique" University Hospital of Angers and especially Mr Jean-Marie Chretien, for Data Acquisition.

Author's contribution Aurélien Venara, Antoine Hamy and Michel Neunlist contributed to conception, design, analysis and interpretation of data, manuscript author; provided criticism of the manuscript; drafted the article and revised it critically for important intellectual content; and approved the final version to be published. Emilie Duchalais, Anne Dariel, Philippe Aubert and Tony Durand helped in data collection and experimentation, provided criticism of the manuscript, drafted the article and approved the final version to be published. Guillaume Meurette and Malvyne Rolli-Derkinderen drafted the article and revised it critically for important intellectual content and approved the final version to be published.

\section{Compliance with ethical standards}

Conflict of interest Aurélien Venara has been invited to clinical congresses by Nestlé. Emilie Duchalais, Anne Dariel, Philippe Aubert, Tony Durand, Guillaume Meurette, Malvyne Rolli-Derkinderen, Antoine Hamy and Michel Neunlist declare no conflict of interest in relation with the present manuscript.

\section{References}

1. Senagore AJ (2007) Pathogenesis and clinical and economic consequences of postoperative ileus. Am J Health-Syst Pharm 64:S3-S7

2. Asgeirsson T, El-Badawi KI, Mahmood A, Barletta Luchtefeld M, Senagore AJ (2010) Postoperative ileus: it costs more than you expect. J Am Coll Surg 210:228-231

3. Livingston EH, Passaro EP (1990) Postoperative ileus. Dig Dis Sci 35:121-132

4. Traut U, Brügger L, Kunz R, Pauli-Magnus C, Haug K, Bucher HC, Koller MT (2008) Systemic prokinetic pharmacologic treatment for postoperative adynamic ileus following abdominal surgery in adults. Cochrane Database Syst Rev 23:CD004930

5. Chen J-Y, Ko T-L, Wen Y-R, Wu SC, Chu YH, Yien HW, Kuo CD (2009) Opioid-sparing effects of ketorolac and its correlation with the recovery of postoperative bowel function in colorectal surgery patients: a prospective randomized double-blinded study. Clin J Pain 25:485-489

6. Schlachta CM, Burpee SE, Fernandez C, Chan B, Mamazza J, Poulin EC (2007) Optimizing recovery after laparoscopic colon surgery (ORAL-CS): effect of intravenous ketorolac on length of hospital stay. Surg Endosc 21:2212-2219

7. Lubbers T, Buurman W, Luyer M (2010) Controlling postoperative ileus by vagal activation. World $\mathrm{J}$ Gastroenterol 16:1683-1687

8. Kobayashi T, Masaki T, Kogawa K, Matsuoka H, Sugiyama M (2015) Efficacy of gum chewing on bowel movement after open colectomy for left-sided colorectal cancer: a randomized clinical trial. Dis Colon Rectum 58:1058-1063

9. Atkinson C, Penfold CM, Ness AR, Longman RJ, Thomas SJ, Hollingworth W, Kandiyali R, Leary SD, Lewis SJ (2016) Randomized clinical trial of postoperative chewing gum versus standard care after colorectal resection. Br J Surg 103:962970

10. Fujii T, Morita H, Sutoh T, Yajima R, Yamagushi S, Tsutsumi S, Asao T, Kuwano H (2014) Benefit of oral feeding as early as one day after elective surgery for colorectal cancer: oral feeding on first versus second postoperative day. Int Surg 99:211-215

11. El Nakeeb A, Fikry A, El Metwally T, Fouda E, Youssef M, Ghazi H, Badr S, Khafagy W, Farid M (2009) Early oral feeding in patients undergoing elective colonic anastomosis. Int J Surg 7:206-209

12. Gustafsson UO, Scott MJ, Schwenk W, Demartines N, Roulin D, Francis N, McNaught CE, Macfie J, Liberman AS, Soop M, Hill A, Kennedy RH, Lobo DN, Fearon K, Ljunqvist O (2013) Guidelines for perioperative care in elective colonic surgery: enhanced Recovery After Surgery (ERAS $\left.\left({ }^{\circledR}\right)\right)$ Society recommendations. World J Surg 37:259-284

13. Nygren J, Thacker J, Carli F, Fearon KC, Nordeval S, Lobo DN, Ljungqvist O, Soop M, Ramirez J (2013) Guidelines for perioperative care in elective rectal/pelvic surgery: enhanced Recovery After Surgery (ERAS $\left({ }^{\circledR}\right)$ ) Society recommendations. World J Surg 37:285-305

14. Spanjersberg WR, Reurings J, Keus F, Van Laarhoven CJ (2011) Fast track surgery versus conventional recovery strategies for colorectal surgery. Cochrane Database Syst Rev 16:CD007635

15. Barbieux J, Hamy A, Talbot MF, Casa C, Mucci S, Lermite E, Venara A (2016) Does enhanced recovery reduce postoperative ileus after colorectal surgery? J Visc Surg 2016:S1878-S7886

16. van Bree SHW, van Bree S, Vlug MS, Hollmann MW, Ubbink DT, Zwinderman AH, de Jonge WJ, Snoek SA, Bolhuis K, van der Zanden E, The FO, Bennink RJ, Boeckxstaens GE (2011) Faster recovery of gastrointestinal transit after laparoscopy and fast-track care in patients undergoing colonic surgery. Gastroenterology 141:872-880

17. Wu Z, Boersema GSA, Jeekel J, Lange JF (2014) Nicotine gum chewing: a novel strategy to shorten duration of postoperative ileus via vagus nerve activation. Med Hypotheses 83:352-354

18. van den Heijkant TC, Costes LMM, van der Lee DGC, Aerts B, Osinga-de Jong M, Rutten HR, Hulsewe KW, de Jonge WJ, Buurman WA, Luyer MD (2015) Randomized clinical trial of the effect of gum chewing on postoperative ileus and inflammation in colorectal surgery. Br J Surg 102:202-211

19. Gong J, Xie Z, Zhang T, Gu L, Yao W, Guo Z, Li Y, Lu N, Zhu W, Li N, Li J (2016) Randomised clinical trial: prucalopride, a colonic pro-motility agent, reduces the duration of post-operative 
ileus after elective gastrointestinal surgery. Aliment Pharmacol Ther 43:778-789

20. Schwarz NT, Kalff JC, Türler A, Speidel N, Grandis JR, Billiar TR, Bauer AJ (2004) Selective jejunal manipulation causes postoperative pan-enteric inflammation and dysmotility. Gastroenterology 126:159-169

21. Berthoud HR, Carlson NR, Powley TL (1991) Topography of efferent vagal innervation of the rat gastrointestinal tract. Am J Physiol 260(1 Pt 2):R200-R207

22. Schwarz NT, Kalff JC, Türler A, Engel DM, Watkins SC, Billiar TR, Bauer AJ (2001) Prostanoid production via COX-2 as a causative mechanism of rodent postoperative ileus. Gastroenterology 121:1354-1371

23. Kalff JC, Türler A, Schwarz NT, Schraut WH, Lee KK, Tweardy DJ, Billiar TR, Simmons RL, Bauer AJ (2003) Intra-abdominal activation of a local inflammatory response within the human muscularis externa during laparotomy. Ann Surg 237:301-315

24. Korolkiewicz RP, Sein-Anand J, Ruczyński J, Rekowski P, Bieniaszewski L, Chodrowski Z, Petrusewicz J, Ujda M, Dabkowski J, Bitel M, Kato S, Takeuchi K (2004) The role and interactions of nitric oxide (NO), carbon monoxide (CO), and prostanoids in the pathogenesis of postoperative ileus in rats. J Gastrointest Surg 8:346-357

25. Wattchow DA, De Fontgalland D, Bampton PA, Leach PL, Mclaughlin K, Costa M (2009) Clinical trial: the impact of cyclooxygenase inhibitors on gastrointestinal recovery after major surgery - a randomized double blind controlled trial of celeCOXib or diclofenac vs. placebo. Aliment Pharmacol Ther 30:987-998

26. Martinez-Cutillas M, Mañé N, Gallego D, Jimenez M, Martin MT (2014) EP2 and EP4 receptors mediate PGE2 induced relaxation in murine colonic circular muscle: pharmacological characterization. Pharmacol Res 90:76-86

27. Tajima T, Murata T, Aritake K, Urade Y, Michishita M, Matsuoka T, Narumiya S, Osaki H, Hori M (2012) EP2 and EP4 receptors on muscularis resident macrophages mediate LPS-induced intestinal dysmotility via iNOS upregulation through cAMP/ERK signals. Am J Physiol Gastrointest Liver Physiol 302:G524-G534

28. Kreiss C, Birder LA, Kiss S, VanBibber MM, Bauer AJ (2003) COX-2 dependent inflammation increases spinal Fos expression during rodent postoperative ileus. Gut 52:527-534

29. Diener M, Gabato D (1994) Thromboxane-like actions of prostaglandin D2 on the contractility of the rat colon in vitro. Acta Physiol Scand 150:95-101
30. Shahbazian A, Heinemann A, Peskar BA, Holzer P (2002) Differential peristaltic motor effects of prostanoid (DP, EP, IP, TP) and leukotriene receptor agonists in the guinea-pig isolated small intestine. Br J Pharmacol 137:1047-1054

31. van Bree SHW, Bemelman WA, Hollmann MW, Zwinderman AH, Matteoli G, El Temna S, The FO, Vlug MS, Bennink RJ, Boeckxstaens GE (2014) Identification of clinical outcome measures for recovery of gastrointestinal motility in postoperative ileus. Ann Surg 259:708-714

32. Vather R, Trivedi S, Bissett I (2013) Defining postoperative ileus: results of a systematic review and global survey. J Gastrointest Surg 17:962-972

33. Sista F, Schietroma M, Santis GD, Mattei A, Cecilia EM, Piccione F, Leardi S, Carlei F, Amicucci G (2013) Systemic inflammation and immune response after laparotomy vs laparoscopy in patients with acute cholecystitis, complicated by peritonitis. World J Gastrointest Surg 5:73-82

34. Park SW, Lee SG, Song SH, Heo DS, Park BJ, Lee DW, Kim KH, Sung MW (2003) The effect of nitric oxide on cyclooxygenase-2 (COX-2) overexpression in head and neck cancer cell lines. Int J Cancer 107:729-738

35. Meile T, Glatzle J, Habermann FM, Kreis ME, Zittel TT (2006) Nitric oxide synthase inhibition results in immediate postoperative recovery of gastric, small intestinal and colonic motility in awake rats. Int J Colorectal Dis 21:121-129

36. Dandona P, Chaudhuri A, Mohanty P, Ghanim H (2007) Antiinflammatory effects of insulin. Curr Opin Clin Nutr Metab Care 10:511-517

37. Paulasir S, Kaoutzanis C, Welch KB, Vandewarker JF, Krapohl G, Lampman RM, Franz MG, Cleary RK (2015) Nonsteroidal antiinflammatory drugs: Do they increase the risk of anastomotic leaks following colorectal operations? Dis Colon Rectum 58:870-877

38. Kotagal M, Hakkarainen TW, Simianu VV, Beck SJ, AlfonsoCristancho R, Flum DR (2016) Ketorolac use and postoperative complications in gastrointestinal surgery. Ann Surg 263:71-75

39. Hakkarainen TW, Steele SR, Bastaworous A, Dellinger EP, Farrokhi E, Farjah F, Florence M, Helton S, Horton M, Pietro M, Varghese TK, Flum DR (2015) Nonsteroidal anti-inflammatory drugs and the risk for anastomotic failure: a report from Washington State's Surgical Care and Outcomes Assessment Program (SCOAP). JAMA Surg 150:223-228

40. Perrone L, Devi TS, Hosoya K, Terasaki T, Singh LP (2009) Thioredoxin interacting protein (TXNIP) induces inflammation through chromatin modification in retinal capillary endothelial cells under diabetic conditions. J Cell Physiol 221:262-272 